\section{Assimilative Lighting with High- pressure Sodium Lamps Reduces Freesia Quality}

Theo J. Blom and Brian D. Piott

Horticultural Research Institute of Ontario, Vineland Station, Ont. LOR 2E0, Canada

Additional index words. photoperiod, production, corm

Abstract. Four freesia cultivars were exposed to 24 hour-day ${ }^{-1}$ high-pressure sodium (HPS) lighting during various stages of their development. Upon emergence, freesia plants were exposed to the following four lighting treatments: 1) ambient; 2) ambient until shoot length was 5 to $8 \mathrm{~cm}$ followed by HPS lighting until flowering; 3) HPS lighting until shoot length was 5 to $8 \mathrm{~cm}$ followed by ambient lighting; and 4) continuous HPS lighting. Supplemental HPS lighting was provided at $37 \mu \mathrm{mol} \cdot \mathrm{m}^{-2} \cdot \mathrm{s}^{-1}$ at plant level in a glasshouse. Continuous lighting or lighting during flower development hastened flowering but reduced the number of flowering stems per corm, as well as stem length and weight. Lighting during the vegetative and flower initiation periods produced minor effects. The main benefit of supplemental lighting was found in total corm weight.

There have been mixed results of the effects of short days (SD) on flower initiation and the number of flowers in freesia production (Heide, 1965; Mansour, 1968). De Lint (1969), Kawata (1973), and GilbertsonFerriss and Wilkins (1978) showed that long days stimulated and accelerated flower development in comparison with SD. Supplemental assimilative lighting using highpressure sodium (HPS) lamps (16-h photoperiod) applied during flower development increased the production and quality of cut freesias during the winter in The Netherlands (Doorduin and Zwinkels, 1990).

The objective of this study was to evaluate the effects of continuous supplemental as-

Received for publication 13 Jan. 1992. Accepted for publication 17 June 1992. The cost of publishing this paper was defrayed in part by the payment of page charges. Under postal regulations, this paper therefore must be hereby marked $a d$ vertisement solely to indicate this fact. similative lighting applied during different forcing stages on production and flowering of cut freesias under North American conditions.

On 18 Oct. 1990, 21 corms, 6 to $7 \mathrm{~cm}$ in circumference, of four Freesia $\times$ hybrida Bailey cultivars (Athene, Aurora, Ballerina, and Butterfly) were planted at a 2- to $3-\mathrm{cm}$ depth in $45 \times 45 \times 18 . \mathrm{cm}$ (length $\times$ width $x$ height) plastic perforated crates and placed in a $110-\mathrm{m}^{2}$ glasshouse. Pretreated corms (14 weeks at 30C) were air-freighted from Flamingo Holland (Honselersdijk, The Netherlands). There were eight crates of each cultivar. The growing medium consisted of $50 \%$ peatmoss, $35 \%$ vermiculite (medium grade), and $15 \%$ turface (by volume), amended with $\left(\mathrm{kg} \cdot \mathrm{m}^{-3}\right) 3.5$ calcitic limestone, 1.5 superphosphate, and 0.5 magnesium sulphate, and with $325 \mathrm{~g}$ of "Soilwet" (microelements and wetting agent on microfine vermiculite) per cubic meter of mix. The initial $\mathrm{pH}$ was 6.2 and the electrical conduc- tivity was $0.9 \mathrm{mS} \cdot \mathrm{cm}^{-1}$ using saturated paste extraction. The air at plant level was set at $16 \mathrm{C}$ during the first 5 weeks (seven to eight leaves visible), $14 \mathrm{C}$ during the next 5 weeks (flower stems 5 to $8 \mathrm{~cm}$ long), and $12 \mathrm{C}$ after 31 Dec. Plants were irrigated once a week with water only between 18 Oct. and 23 Nov., and thereafter every 7 to 14 days along with 100 ppm N using 20N-2.2P-25K. Secondary shoots on the original corms (splitters) were removed upon emergence.

Upon emergence of shoots (6 Nov. 1990), the crates were divided into two separate blocks and placed under 1) ambient (no artificial light) or 2) lighted (HPS lights with $37 \mu \mathrm{mol} \cdot \mathrm{m}^{-2} \cdot \mathrm{s}^{-1}$ at plant level for $24 \mathrm{~h} \cdot \mathrm{day}^{-1}$ conditions for 18 weeks. After 8 weeks under the two lighting regimes (period 1, the plants had completed leaf and flower initiation, and main shoot had elongated to 5 to $8 \mathrm{~cm}$ long as determined under a dissecting microscope., Subsequently, half the crates from each ambient area were placed under a reciprocal lighting regime. The remaining crates stayed at the original location. Plants were grown under these lighting regimes for an additional 10 weeks (period 2) until the end of flowering, 12 Mar. 1991. This procedure resulted in four lighting treatments: AA, continuous ambient; AH, ambient followed by HPS lighting; HA, HPS lighting followed by ambient; and $\mathrm{HH}$, continuous HPS lighting. A permanent vertical black cloth together with a movable horizontal black-out system, drawn daily between 1800 and 0600 HR, prevented light contamination of the ambient areas. Circulation fans positioned in the vertical curtains minimized differences in air temperature between lighted areas.

Repeated (daily) measurements for each crate (experimental unit) were recorded as follows: production, number of flowering stems; harvesting period, first day of harvest after planting (FDH) and the day $70 \%$ of total stems were harvested $(70 \mathrm{H})$; and quality, fresh weight and stem length of flowering stem and number of colored flowers per spike. In addition, total corm (main corm 
Table 1. Performance of four freesia cultivars grown under two lighting regimes [high-pressure sodium (HPS) lights for $24 \mathrm{~h} \cdot \mathrm{day}^{-1}$ and ambient] applied during two periods.

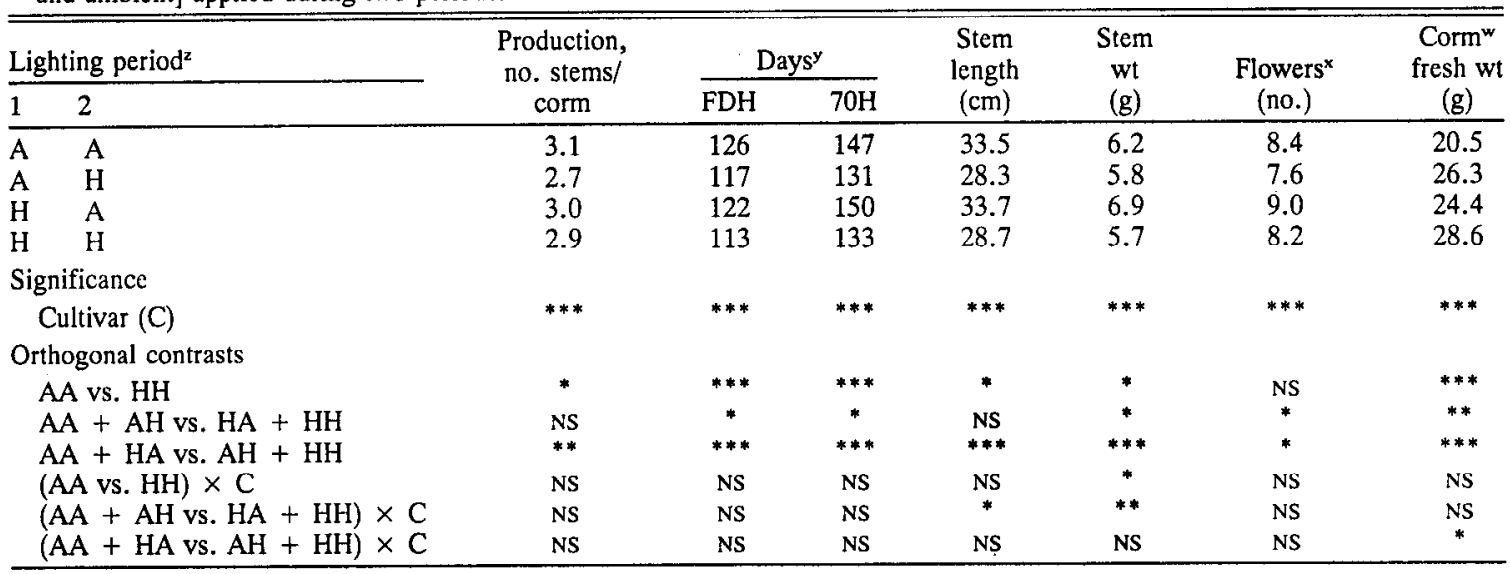

2Period 1 is weeks $2-10$ and period 2 is weeks $10-18$ after planting; $A=$ ambient; $H=$ HPS lighting.

yFDH is first day of harvest after planting; $70 \mathrm{H}$ is date at which $70 \%$ of total harvest is achieved after planting. Corms planted on 18 Oct.

${ }^{x}$ Number of flowers showing color per spike.

wotal fresh weight of corms was determined 12 weeks after $70 \mathrm{H}$.

Ns,*,*****Nonsignificant or significant at $0.01<P<0.05 ; 0.005<P<0.01$; or $P<0.0005$, respectively.

+ cormlets) weights were determined 3 months after $70 \mathrm{H}$.

The experiment was analyzed as a splitblock design with blocks (two) and lighting (four) as whole plots and cultivars (four) as subplots. Preliminary analysis of the data on quality aspects showed that sampling error was not significantly different from subplot error. This indicated that correlations among observations were small. Therefore, the quality responses were averaged for each crate before analysis. Orthogonal contrasts were determined for the effect of continuous $(\mathrm{HH}$ vs. AA) lighting, and the average effect of period $1(\mathrm{AA}+\mathrm{AH}$ vs. $\mathrm{HA}+\mathrm{HH})$ and period 2 (AA + HA vs. $\mathrm{AH}+\mathrm{HH})$ lighting were compared to ambient.

Production. Continuous and period 2 lighting reduced the number of flowering stems by $\approx 0.2$ stems per corm. Period 1 lighting did not affect production compared with ambient (Table 1).

Harvesting period. Continuous 24-h lighting hastened $\mathrm{FDH}$ and $70 \mathrm{H}$ by 2 weeks and had no effect on harvest duration (70H-FDH) when compared with-ambient lighting (Table 1). Period 1 lighting hastened FDH but delayed $70 \mathrm{H}$, which resulted in a 1-week extension of the harvest period. Thus, period 1 lighting hastened flowering of the main stem but delayed the development of side breaks. This finding is contrary to that of
Mansour (1968) that flower initiation was stimulated by SD. Also, period 2 lighting hastened harvest but shortened harvest duration by 1 week when compared with ambient lighting, possibly due to a higher plant temperature from assimilative lighting.

Quality. Continuous and period 2 lighting reduced stem length and weight compared with ambient lighting. Period 1 lighting resulted only in increased stem length for 'Ballerina' and increased stem weight for 'Athene' and 'Butterfly'. While continuous lighting had no net effect on the number of flowers per spike, their number was increased by period $1(+0.8)$, but decreased by period 2 (-0.7) lighting.

Corm production. The relatively large increase $(40 \%)$ in total corm weight from continuous lighting was similar in magnitude to the $45 \%$ daily lightsum (total integrated irradiation) increase (average for December, January, and February) at plant level. However, there was a larger increase in corm weight during period $2(23 \%)$ than during period $1(13 \%)$. The number of cormlets was not affected by lighting (data not shown).

These results were similar to crops of the previous year (unpublished) but contrary to results (production and quality) with lighting with 'Blue Heaven' conducted at $56^{\circ} \mathrm{N}$ (Doorduin and Zwinkels, 1990). The latter experiment was also conducted during the winter, but with 16-h daylength and at onehalf of the global radiation received at our latitude $\left(43^{\circ} \mathrm{N}\right)$. Our experiment showed that assimilative 24-h lighting for commercial purposes at latitudes below $45^{\circ} \mathrm{N}$ or $45^{\circ} \mathrm{S}$ cannot be recommended at this time. Future lighting studies with cut freesias should include different daylengths, temperatures, and cultivars with higher light requirements, and different initial corm sizes at time of planting.

\section{Literature Cited}

De Lint, P.J.A.L. 1969. Flowering in Freesia: Temperature and corms. Acta Hort. 14:125-131. Doorduin, J.C. and G.A.M. Zwinkels. 1990. Assimilation lighting for Freesia. Positive effects in every respect. Vakblad voor de Bloemisterij 45(36):42-43.

Gilbertson-Ferriss, T.L. and H.F. Wilkins. 1978. Flower production of Freesia hybrida seedlings under night interruption lighting and short day influence. J. Amer. Soc. Hort. Sci. 103:587591.

Heide, O.M. 1965. Factors controlling flowering in seed-raised Freesia plants. J. Hort. Sci. 40:267-284

Kawata, J. 1973. Year-round production of Freesia in Japan. Jpn. Agr. Res. Quart. 7:257-262.

Mansour, B.M.M. 1968. Effect of temperature and light on growth, flowering and corm formation in Freesia. Meded. Landbouw Hogeschool. Wageningen 68(8):1-76. 